\title{
Learning Needs Assessment of Pediatric Nurses Regarding Delirium and Its Barriers of Screening at Intensive Care Units
}

\author{
Fawzia El Sayed Abusaad $^{1, *}$, Marwa Fathallah Mostafa $^{2}$, Adel El Wehedy Ibraheim ${ }^{3}$ \\ ${ }^{1}$ Pediatric Nursing Department, Faculty of Nursing, Mansoura University, Egypt \\ ${ }^{2}$ Critical Care and Emergency Nursing, Faculty of Nursing, Mansoura University, Egypt \\ ${ }^{3}$ Community Health Medicine, Faculty of Medicine, Mansoura University, Egypt \\ *Corresponding author: fawziaabusaad2013@gmail.com
}

\begin{abstract}
Pediatric delirium is a significant issue among critically ill children; Professional and highly qualified nurses are usually the first who identify delirium in ICU patients, with a need for close monitoring, recognition, and prevention. Aim of the study was to assess learning needs of critical care nurses regarding pediatric delirium and its barrier of screening at ICUs. Method: A descriptive design was conducted on a purposive sample of 91 pediatric critical care nurses working at Mansoura University Children's hospital and New Mansoura General hospital who fulfills the criteria of selection using pediatric nurses learning needs structured questionnaire that includes questions about characteristics of studied nurses, nurse's knowledge, attitude and practice about pediatric delirium and barriers of delirium screening among pediatric critical care nurses. Results: the level of nurses' knowledge was poor in 94.5\%, fair in 5.5\% and there was any one with good knowledge, the negative attitude toward delirium was reported in $54.9 \%$ of nurses, while only $3.3 \%$ of nurses has positive attitude and the level of practice was unsatisfactory in $81.3 \%$ of nurses. The most common barriers for delirium screening as reported by the studied nurses is absent of tool to evaluate delirium (86.8\%), difficult to determine delirium in children on ventilator (78.0\%) and inefficient of symptoms registering in children taking sedation (70.3\%). Conclusions: the majority of studied nurses have poor knowledge about pediatric delirium particularly for its definition, causes and its management. Also, more than half of them has negative attitude regarding delirium and majority of them has unsatisfactory practice. The commonest barriers for delirium screening were absent of tool and difficulties of delirium screening for children on ventilator at ICUs. Recommendation: pediatric critical care nurses learning needs should be assessed constantly and progressively through implementing educational training program to increase competences of Pediatric ICUs staff focused on practical guidelines for hospitalized children with delirium.
\end{abstract}

Keywords: pediatric delirium, critical care nurses, knowledge, attitude, practice, barriers

Cite This Article: Fawzia El Sayed Abusaad, Marwa Fathallah Mostafa, and Adel El Wehedy Ibraheim, "Learning Needs Assessment of Pediatric Nurses Regarding Delirium and Its Barriers of Screening at Intensive Care Units.” American Journal of Nursing Research, vol. 5, no. 3 (2017): 70-78. doi: 10.12691/ajnr-5-3-1.

\section{Introduction}

Delirium in critically ill children represents acute brain dysfunction and is characterized by a range of alteration in mental states and behaviors. American psychiatric association, 2013 defines delirium as an etiologically nonspecific organic cerebral syndrome characterized by concurrent disturbances of consciousness and attention, perception, thinking, memory, psychomotor behavior, emotion, and the sleep-wake schedule, its duration is variable and the degree of severity ranges from mild to very severe [1].

The Diagnostic and Statistical Manual of Mental Disorders (DSM-IV) definition of delirium involves acute onset, fluctuating course, and two major categories: disturbance of consciousness (including attention and awareness) and cognition disturbance (including memory, orientation, language, and perception), that results from a medical condition, can be caused by the illness itself, by products of the illness, or side-effects of the treatment [2].

Severity of the illness, number of medications; diagnostic tools used, and group under study either pediatric ICU patients or in general ward considered from the risk factors of delirium. Mental retardation and the previous episode of delirium are also known as risk factors. As well as numerous conditions, including sepsis, hypoxia, sedative exposure, and others, contribute to delirium during critical illness. It is unknown whether adverse long-term cognitive outcomes associated with delirium are predicted by specific risk factor-defined subtypes or by all subtypes of delirium [3].

Delirium can present itself in three forms: hyperactive, hypoactive and mixed. A systematic review revealed the 
prevalence rate of delirium in patients upon admission range from $10 \%$ to $31 \%$ depending on the age of children. In pediatric patients, delirium often goes unrecognized, despite its prevalence [4].

One study found delirium occurs in more than $30 \%$ of children ages 2 to 5 and more than $50 \%$ of critically ill children younger than age 2. Another study uncovered delirium in $20 \%$ of patients from birth to age 21 in the study population [5].

In hyperactive delirium, the presented behaviors may include agitation, restlessness, combativeness, and pulling at I.V lines or an endotracheal tube. The easiest subtype to recognize, hyperactive delirium is what most healthcare professionals think of when they hear the word delirium. While, a study of children younger than age 5 who tested positive for delirium, only $7 \%$ showed hyperactive subtype behaviors. While In hypoactive delirium, the child seems sedate or apathetic, and appears withdrawn from people or the environment. These children seem comfortable but with something amiss. It consider the most common subtype in children younger than age 5, accounts for about $60 \%$ of children diagnosed with delirium and often goes unrecognized. However in mixed delirium, the children meets all the criteria for delirium and displays some behaviors typical of both hyperactive and hypoactive delirium [6].

Delirium is a frequent condition in Intensive Care Unit (ICU) patients with limited options for prevention and therapy. Whereas, non-pharmacological strategies can prevent delirium in non-ICU patients, still the ICU environment with continuous light and noise, around the clock personnel and lack of orientation points is assumed to play a role in the development of delirium [7].

Because delirium reportedly occurs in up to $87 \%$ of ICU patients receiving mechanical ventilation, the Society of Critical Care Medicine practice guidelines recommend that ICU patients be routinely screened for delirium by using a validated screening tool. Prompt recognition of delirium in the ICU allows nurses to differentiate children symptoms (e.g., pain, anxiety) from other conditions with similar features (e.g., psychomotor agitation) and facilitates the initiation of both drug and non drug therapies. Adverse events include prolonged ICU stay and length of hospital stay (LOS), higher mortality, selfextubation, self-removal of catheters and increased costs as well as long-term cognitive impairment $[8,9]$.

Nurses are in better position to assess their attitude because of the amount of time they spent beside critical child. If nurses don't have the necessary knowledge and skills to evaluate child carefully, they cannot intervene early enough to prevent further deterioration that increase length of hospital stay [10].

Critical care nurses need to increase their awareness about delirium among children in the ICU in order to detect it early, treat it and decrease negative outcomes. It's much easier to treat early delirium than it is to treat delirium that has been entrenched for several days [9].

There is a large body of research about delirium in adult ICU patients, but far less in pediatric critical care. Few data are available on nurses' current practices in delirium assessment, the potential barriers for delirium assessment, the early detection and management of children experiencing ICU delirium. Therefore; when nurses apply knowledge of potential causes and coordinate with other health members team to initiate prompt treatment actions, this can be helpful in detecting and consequently preventing occurrence of delirium.

\subsection{Significance of the Study}

Pediatric delirium incidence varies and there is no recorded data about it in pediatric intensive care units at Mansoura University Children's Hospital and New Mansoura General Hospital which may indicated misdiagnosis of delirium, improper treatment or even neglected from health professional that may increase morbidity and mortality among critical pediatric population. Because nurses are at the patient's bedside more consistently than other clinicians, therefore, there is a need for such research that intend to determine the delirium-related knowledge, attitude, and practices among pediatric critical care nurses as well as its barrier of screening at pediatric intensive care units.

\subsection{Aim}

The aim of this study was to assess learning needs of pediatric critical care nurses about delirium and its barrier of screening at intensive care units.

\subsection{Research Questions:}

1- What are the learning needs of critical care nurses regarding pediatric delirium?

2- What are the common barriers of pediatric delirium screening at intensive care units?

\subsection{Operational Definition}

The learning needs of pediatric critical care nurses means their knowledge recognition, their attitude and their practical knowledge regarding delirium.

\section{Subjects and Methods}

\subsection{Research Design}

A descriptive design was used to conduct this study.

\subsection{Research Setting}

This study was conducted at Pediatric Intensive Care Units of Mansoura University Children Hospitals (MUCH) and New Mansoura General Hospital (NMGH). All pediatric intensive care units were selected as; Cardiac ICU, General Pediatric ICU from MUCH as well as Neurological ICU, and Pediatric ICU from NMGH .

\subsection{Subjects}

A purposive sample of 91 nurses who are working in intensive care units,51 nurses from MUCH and 40 from $\mathrm{NMGH}$, who are willing to participate with various levels of education and have at least one year of work experience in Pediatric intensive care units. 


\subsection{Tools of the Study}

Pediatric nurses structured questionnaire: it was developed by the researcher after reviewing the related literature [11,12]. It was developed in Arabic language to accomplish the purpose of this study; it composed of three parts:

Part I: Characteristics of studied nurse it was included age, sex, educational level, years of experience and previous training program on delirium.

Part II: Nurses learning needs assessment: this part consisted of

a. Nurse's knowledge about pediatric delirium; 15 questions that based on related researches [11,12]. It was modified by the researcher to measure pediatric critical care nurses knowledge about delirium such as definition, incidence, predisposing factors, delirium subtypes, signs and symptoms of each types, delirium assessment methods, and Delirium management and prevention.

\section{Scoring system:}

The total score was 30. Score 2 was given for complete correct answer, score 1 was given for correct incomplete answer and score 0 was given to wrong answer.

The level of knowledge was categorized as follow:

- Good knowledge (75\% and more) (22.5-30 grade).

- Fair knowledge (50\% - >75\%) (15- > 22.5 grade).

- Poor knowledge ( $>50 \%$ ( $>15$ grade).

b. Nurse's attitude and practice about pediatric delirium: 21 questions; 9 questions about pediatric critical care nurses attitude toward the risk factors and characteristics of delirium child. And 11 questions for nursing intervention according to [13].

\section{Scoring system:}

Score 0 was given for disagree and score 1 given for agree. The total score of attitude was 9 and categorized into; Negative attitude (score 3 and less), natural attitude (score from 4-6) and positive attitude (score 7 and more).while

Total score of nurses practice were 11 categorized as:

- $\quad$ satisfactory $(\geq 60 \%)$

- unsatisfactory $(<60 \%)$.

The higher the scores were, the higher it indicated that the levels of delirium-related recognition and practice were.

Part III: Barrier of delirium screening at pediatric intensive care units: 10 items include the possible common barriers of delirium screening from the nurse's point of view that developed by the researcher. Score 1 was given for yes, score 2 given for no and score 3 was given for don't know the answer.

\section{Methods}

\subsection{Ethical Consideration}

An ethical approval for conducting this study was obtained from the Ethics Committee of Faculty of Nursing, Mansoura University before beginning the study.

All nurses in each ICUs of the two hospital's (MUCH and NMGH) were learned about the study aim orally and invited to participate. They were informed that participation was completely voluntary and right to withdrawal from participation in the study could take place at any time. Confidentiality and anonymity were also assured.

The assessment tool of learning needs was developed after extensive review of related literature.

\subsection{Validity and Reliability}

The tool was tested for content validity by 5 experts in pediatric critical care medicine and nursing who reviewed the tool for clarity, relevance, understanding and applicability.

The reliability of the tool was estimated using cronbach's alpha reliability test showed a positive significance with ( $\mathrm{r}=.79 \%)$

The questionnaire was pilot-tested for face validity and clarity by a random sample of 5 pediatric critical care nurses, minor modification was done and the pilot sample excluded from the study.

\subsection{Data Collection Procedure}

In both hospitals (MUCH and NMGH), Nurses who agreed to participate in the study were interviewed individually for 15-20 minutes by the researcher to fill the tool. The data were collected through the three shifts, "morning, afternoon and night " and according to their schedule predetermined during a period of 2 month (from the beginning of January to the end of February 2017).

\subsection{Statistical Analysis}

Data were collected, coded, computed and statistically analyzed using SPSS soft war program version16. The qualitative categorical variables were presented in tables as frequency and percentage. The qualitative variables were presented as mean \pm SD.

\section{Results}

The data collected were analyzed statistically and the results were categorized into 3 main parts which are: Characteristics of studied nurse, nurses learning needs assessment, and barrier of delirium screening among pediatric critical care nurses.

Table 1 shows that, among 91 nurses working in pediatric ICUs, 51 (56.0\%) were working in MUH and 40 (44.0) were working in New Mansoura General Hospital (NMGH). As regard type of ICU; 19 (20.9\%) of nurses were working in cardiac ICU, while $63.7 \%$ and $15.4 \%$ were working in general and neurological ICUs units respectively. The age of nurses ranges from 21.0 to 39.0 years with Mean $29.32 \pm 4.72$ years. All of nurses were females. Their education was nursing diploma (8.8\%), nursing institute (16.5\%), bachelor's (73.6\%) and master (1.1\%). Nurses' experience ranges from 1.0 to 16.0 years with Mean $6.62 \pm 3.99$ years and only $6.6 \%$ had previous training.

Table 2 and Figure 1 show the distribution of the studied nurses according their knowledge about delirium. The correct answer for the knowledge items differed from zero \% like definition, causes and management, up to 
$75.8 \%$ for prevention. The average knowledge score is $7.95 \pm 4.41$, while the level on nurses' knowledge was poor in $94.5 \%$, fair in $5.5 \%$ and there was any one with good knowledge.

Table 1. Characteristics of the studied nurses in percentage distribution

\begin{tabular}{|c|c|c|c|}
\hline Characters & Items & No & $\%$ \\
\hline \multirow{2}{*}{ Type of hospital } & University & 51 & 56.0 \\
\hline & Ministry of health & 40 & 44.0 \\
\hline \multirow{3}{*}{ Type of ICU } & Cardiac & 19 & 20.9 \\
\hline & General & 58 & 63.7 \\
\hline & Neurology & 14 & 15.4 \\
\hline \multirow{6}{*}{ Age } & $20-$ & 15 & 16.5 \\
\hline & $25-$ & 29 & 31.9 \\
\hline & $30-$ & 34 & 37.4 \\
\hline & $35-40$ & 13 & 14.3 \\
\hline & Range & \multirow{2}{*}{\multicolumn{2}{|c|}{$\begin{array}{c}21.0-39.0 \mathrm{y} \\
29.32 \pm 4.72 \mathrm{y}\end{array}$}} \\
\hline & Mean \pm SD & & \\
\hline \multirow{2}{*}{ Sex } & Male & 0 & 0.0 \\
\hline & Female & 91 & 100.0 \\
\hline \multirow{4}{*}{ Education } & Nursing diploma & 8 & 8.8 \\
\hline & Institute & 15 & 16.5 \\
\hline & Bacheloris & 67 & 73.6 \\
\hline & Master & 1 & 1.1 \\
\hline \multirow{6}{*}{ Experience } & Up to one year & 6 & 6.6 \\
\hline & $1-$ & 24 & 26.4 \\
\hline & $5-$ & 35 & 38.5 \\
\hline & $10+$ & 26 & 28.6 \\
\hline & Range & \multirow{2}{*}{\multicolumn{2}{|c|}{$\begin{array}{c}1.0-16.0 \mathrm{y} \\
6.62 \pm 3.99 \mathrm{y}\end{array}$}} \\
\hline & Mean \pm SD & & \\
\hline \multirow{2}{*}{ Previous training delirium program } & Yes & 6 & 6.6 \\
\hline & No & 85 & 93.4 \\
\hline
\end{tabular}

Table 2. Frequency distribution of the studied nurses according their knowledge

\begin{tabular}{|c|c|c|c|c|c|c|}
\hline \multirow{2}{*}{ Items of knowledge } & \multicolumn{2}{|c|}{ Incorrect (0) } & \multicolumn{2}{|c|}{ Partial correct (1) } & \multicolumn{2}{|c|}{ Correct (2) } \\
\hline & No & $\%$ & No & $\%$ & No & $\%$ \\
\hline Definition & 73 & 80.2 & 18 & 19.8 & 0 & 0.0 \\
\hline Incidence & 74 & 81.3 & 4 & 4.4 & 13 & 14.3 \\
\hline Causes & 24 & 26.4 & 67 & 73.7 & 0 & 0.0 \\
\hline Types & 38 & 41.8 & 50 & 54.9 & 3 & 3.3 \\
\hline Signs and symptoms & 30 & 33.0 & 29 & 31.9 & 32 & 35.1 \\
\hline Most common types & 70 & 76.9 & 7 & 7.7 & 14 & 15.4 \\
\hline Hypoactive signs & 79 & 86.8 & 3 & 3.3 & 9 & 9.9 \\
\hline Aggressive child type & 57 & 62.6 & 4 & 4.4 & 30 & 33.0 \\
\hline Prolonged type of delirium & 57 & 82.4 & 5 & 5.5 & 11 & 12.1 \\
\hline High risk factors & 65 & 71.4 & 10 & 11.1 & 16 & 17.6 \\
\hline Time of day increase delirium signs & 62 & 68.1 & 16 & 17.6 & 13 & 14.3 \\
\hline Clinical outcomes of delirium & 36 & 39.6 & 53 & 58.2 & 2 & 2.2 \\
\hline Delirium assessment tool & 75 & 82.4 & 5 & 5.5 & 11 & 12.1 \\
\hline Delirium management & 33 & 36.3 & 58 & 63.7 & 0 & 0.0 \\
\hline Delirium prevention & 22 & 24.2 & 0 & 0.0 & 69 & 75.8 \\
\hline \multicolumn{7}{|l|}{ Knowledge score } \\
\hline Range & \multicolumn{6}{|c|}{$0.0-19.0$} \\
\hline Mean \pm SD & \multicolumn{6}{|c|}{$7.95 \pm 4.41$} \\
\hline \multicolumn{7}{|l|}{ Level of knowledge } \\
\hline Poor knowledge $(<50.0 \%)$ & \multicolumn{6}{|c|}{$86(94.5 \%)$} \\
\hline Fair knowledge (50.0 - <75.0\%) & \multicolumn{6}{|c|}{$5(5.5 \%)$} \\
\hline Good knowledge ( $\geq 75.0 \%$ ) & \multicolumn{6}{|c|}{$0(0.00)$} \\
\hline
\end{tabular}




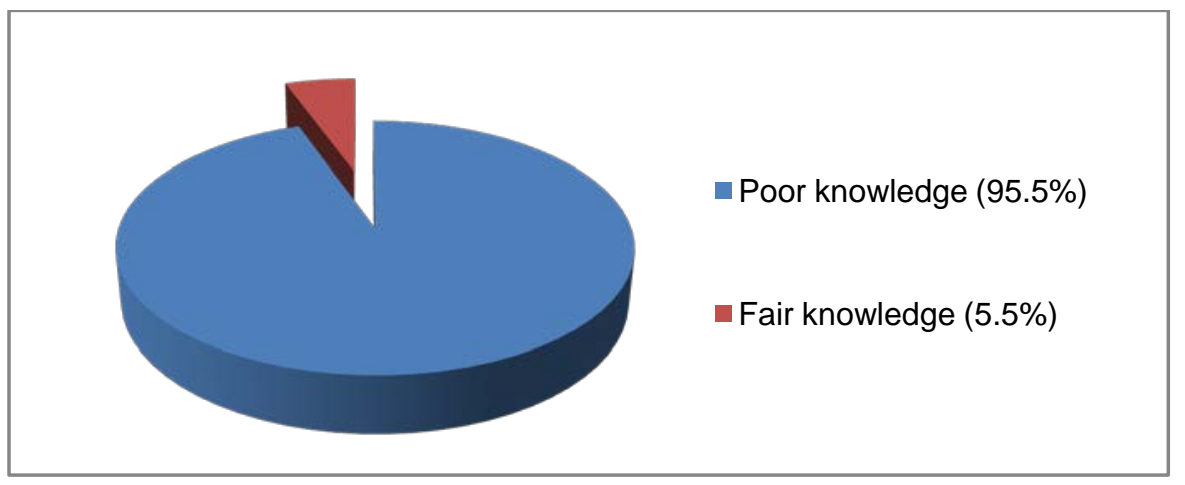

Figure 1. Knowledge level of studied nurses about delirium

Table 3. Frequency distribution of the studied nurses according to their recognized attitude toward pediatric delirium

\begin{tabular}{|c|c|c|c|c|}
\hline \multirow{2}{*}{ Attitude items } & \multicolumn{2}{|c|}{ Disagree } & \multicolumn{2}{|c|}{ Agree } \\
\hline & No & $\%$ & No & $\%$ \\
\hline 1-Flactuation between conscious and unconscious is a delirium sign. & 66 & 72.5 & 25 & 27.5 \\
\hline 2-Child gender is not related to delirium & 43 & 47.3 & 48 & 52.7 \\
\hline 3-Malnutrion is a risk factor of delirium & 40 & 44.0 & 51 & 56.0 \\
\hline 4- Hearing \ visual impairment increase the risk of delirium & 47 & 51.6 & 44 & 48.4 \\
\hline 5- Dehydration from high risk factor of delirium & 55 & 60.4 & 36 & 39.6 \\
\hline 6- Family history of dementia is a risk factor & 51 & 56.0 & 40 & 44.0 \\
\hline 7- Children suffering from delirium are more aggressive verbally and physically. & 61 & 67.0 & 30 & 33.0 \\
\hline 8- use of delirium care bundle increases mortality rate & 64 & 70.3 & 27 & 29.7 \\
\hline 9- delirium care bundle consists of 4 elements & 67 & 73.6 & 24 & 26.4 \\
\hline \multicolumn{5}{|l|}{ Attitude Score } \\
\hline Range & \multicolumn{4}{|c|}{$1.0-9.0$} \\
\hline Mean \pm SD & \multicolumn{4}{|c|}{$3.57 \pm 1.59$} \\
\hline \multicolumn{5}{|l|}{ Attitude Level } \\
\hline Negative attitude $(1.0-3.0)$ & \multicolumn{4}{|c|}{$50(54.9 \% 0$} \\
\hline Neutral attitude (4.0 -6.0) & \multicolumn{4}{|c|}{$38(41.8 \%)$} \\
\hline Positive attitude $(7.0-9.0)$ & \multicolumn{4}{|c|}{$3(3.3 \%)$} \\
\hline
\end{tabular}

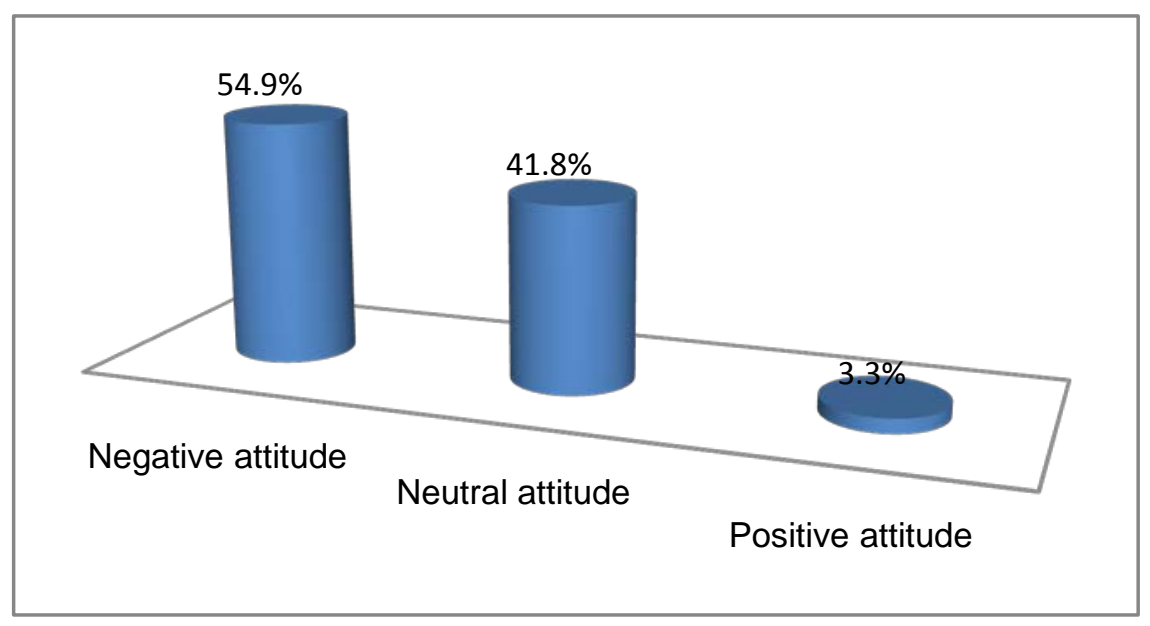

Figure 2. Attitude level of studied nurses about delirium

Table 3 and Figure 2 show distribution of the studied nurses according to their recognized attitude items the negative attitude was reported in $54.9 \%$ of nurses, while neutral attitude.

Table 4 and Figure 3 show the distribution of the studied nurses according to their practical response. The percentage of reported practicing the care items ranges from $45.1 \%$ in sleep pattern changes up to $72.3 \%$ (short period of delirium). The level of practice was unsatisfactory in $81.3 \%$ of nurses and satisfactory in $18.7 \%$.

Table 5 shows distribution of the studied nurses according their reported barriers of delirium screening. The most common barrier reported by the studied nurses is absent of tool to evaluate delirium (86.8\%), difficult to determine delirium in children on ventilator (78.0\%) and inefficient of symptoms registering in children taking sedation (70.3\%). 
Table 4. Frequency distribution of the studied nurses according to their practical response

\begin{tabular}{|c|c|c|c|c|}
\hline \multirow{2}{*}{ Practical items } & \multicolumn{2}{|c|}{ Disagree } & \multicolumn{2}{|c|}{ Agree } \\
\hline & No & $\%$ & No & $\%$ \\
\hline 1-Consciousness assessment is the best methods of diagnosis & 65 & 71.4 & 26 & 28.6 \\
\hline 2-Delirium does not continue for more than hours & 64 & 72.3 & 27 & 29.7 \\
\hline 3-Behavioral changes around the day are a delirium model. & 44 & 48.4 & 47 & 51.6 \\
\hline 4- Sleep\ awake pattern changes is a delirium symptoms & 41 & 45.1 & 50 & 54.9 \\
\hline 5- Noise control is a non pharmacological treatment measures. & 34 & 37.4 & 57 & 62.6 \\
\hline 6- Stimulate child sense is important & 43 & 47.3 & 48 & 52.7 \\
\hline 7- Avoid eye contact is important & 53 & 58.2 & 38 & 41.8 \\
\hline 8- Encourage continuous sleep and immobilization is helpful. & 48 & 52.7 & 43 & 47.3 \\
\hline 9-use benzadiazeben is effective therapy. & 49 & 53.8 & 42 & 46.2 \\
\hline 10-Talk by loud voice to child & 61 & 67.0 & 30 & 33.0 \\
\hline 11-Apply infection control measures can prevent delirium. & 49 & 53.8 & 42 & 46.2 \\
\hline \multicolumn{5}{|l|}{ Practical Score } \\
\hline Range & \multicolumn{4}{|c|}{$1.0-8.0$} \\
\hline Mean \pm SD & \multicolumn{4}{|c|}{$4.94 \pm 1.63$} \\
\hline \multicolumn{5}{|l|}{ Practical Level } \\
\hline Unsatisfactory $(<60.0 \%)$ & \multicolumn{4}{|c|}{$74(81.3 \% 0$} \\
\hline Satisfactory $(\geq 60.0 \%)$ & \multicolumn{4}{|c|}{$17(18.7 \%)$} \\
\hline
\end{tabular}

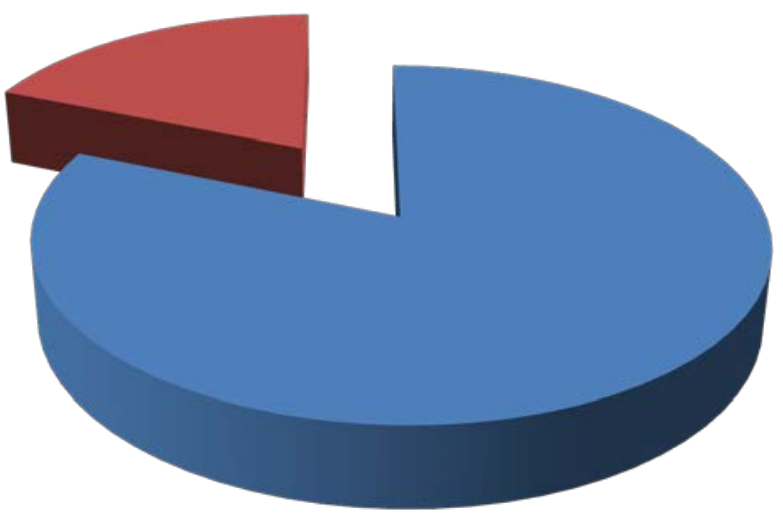

- Unsatisfactory practice $(81.3 \%$

- Satisfactory practice (18.7\%)

Figure 3. Practical level of studied nurses about delirium

Table 5. Frequency distribution of the studied nurses according their reported barriers of delirium screening at ICUs

\begin{tabular}{|l|c|c|c|c|c|c|}
\hline \multirow{2}{*}{ Barriers } & \multicolumn{2}{c|}{ Yes } & \multicolumn{3}{c|}{ No } & \multicolumn{2}{c|}{ Do not know } \\
\cline { 2 - 7 } & No & $\%$ & No & $\%$ & No & $\%$ \\
\hline 1-No tool for delirium evaluation & 79 & 86.8 & 10 & 11.0 & 2 & 2.2 \\
\hline 2-Delirium evaluation tool is difficult in application & 62 & 68.1 & 27 & 29.7 & 2 & 2.2 \\
\hline 3-Delirium is difficult to be determined in children on ventilator & 71 & 78.0 & 19 & 20.9 & 1 & 1.1 \\
\hline 4-I'm not efficient to use the delirium assessment tool & 59 & 64.8 & 31 & 34.1 & 1 & 1.1 \\
\hline 5-my believe is that use of the tool would not improve patient state & 49 & 53.8 & 42 & 46.2 & 0 & 0.0 \\
\hline 6-I cannot recognizes delirium symptom in children taking sedation & 64 & 70.3 & 27 & 29.7 & 0 & 0.0 \\
\hline 7-I have no time determine delirium symptoms at ICUs & 52 & 57.1 & 39 & 42.9 & 0 & 0.0 \\
\hline 8-Determining delirium symptoms is not a nurse responsibility & 44 & 48.4 & 47 & 51.6 & 0 & 0.0 \\
\hline 9-Doctors already determine delirium symptoms and evaluate & 62 & 68.1 & 29 & 31.9 & 0 & 0.0 \\
\hline 10-Doctors do not consider may delirium evaluation & 57 & 62.6 & 34 & 37.4 & 0 & 0.0 \\
\hline
\end{tabular}

\section{Discussion}

The total of the current studied sample was 91 nurses; near three quarters of them (73\%) shipping baccalaureate nursing degree. It may be due to the majority of studied nurses were graduated from faculties of nursing. This result was supported by Glynn \&Corry [14], who searched in critical care nurses opinion and practice regarding delirium in intensive care setting and revealed that (62.3)\% of studied nurses carrying baccalaureate degree. However this finding contradicts with El Nossary et al., [15] who carried out a research on 54 critical care nurses 
about their knowledge and practice regarding delirium and revealed that the majority of the studied nurses hold diploma in nursing. These differences from the researcher point of view may be due to the different types of employment of nursing and variation of the level of patient's acuity in the selected ICUs.

As regard years of experience, the current study revealed that that $38.5 \%$ had 5 to less than 10 years of working experience and $28.6 \%$ the studied nurses has experience more than 10 years (Table 1). The finding agrees with Van dee steeg et al., (2015) [16] results which clarified the same result. However contradicted with Mehrez et al., (2016) [17] who found that critical care nurses in a study of nursing knowledge and perception regarding patient safety has working experience more than 20 years.

Unfortunately, the most majority of studied nurses (93.4\%) have no previous training program in delirium that affect on their knowledge regarding delirium; it may be due to the lack of in service training program which is very important in providing quality of care regarding delirium especially in the pediatric ICU. These finding in the same line with [18], [14] and [15] who revealed that (79.5\%) and (100\%) had never attend any training programs related to delirium.

The results of the current study demonstrated obvious deficit in studied nurses' knowledge regarding specific parts about pediatric delirium such particularly delirium definition, causes and its management as well as little is known about its incidence, types, hypoactive delirium signs and clinical outcomes of pediatric delirium which reflect on their level of knowledge among the majority of nurses that have poor knowledge level (Table 2, Figure 1). This may because delirium is a new studied concept and never studied before as well as not highlighted as an important problem among intensive care pediatric population that accordance with the current result which reflect majority of studied nurses not attend a training program about delirium that leads to under-estimation of almost all knowledge parts among nurses.

These results agreed with previous study done by Ping et al., [19] who founded that the pediatric nurses knew little about the incidence, clinical presentation, treatment and consequence of childhood delirium. Also, Yue, et al., [20] who stated lack of knowledge and skills required to assess and manage the delirium patients lead to preventing nurses from recognizing early symptoms. As well as Trogrlic et al., [21] who made a survey among intensive care unit professionals about their attitude, knowledge and practices concerning delirium, the study indicated that knowledge deficit were presented more clearly in nurses than in physicians. Another supported study made by Flaigle et al., [22] who make a study on 105 nurse and found that nurses who answered each question correctly ranged from $35 \%$ to $100 \%$ and only one nurse scored $100 \%$, the staff required further education regarding the importance, risk factors, and treatments for pediatric delirium. In another study focusing on education, Flagg et al., (2010) [23] administered a survey and found that nurses were lacking in knowledge about the negative results associated with delirium and the importance of routine delirium assessment to enable its early recognition.

Concerning critical care nurses attitude about pediatric delirium, the current results showed that more than half of studied nurses have negative attitude and the minority of them have positive attitude toward delirium (Table 3, Figure 2). From my opinion, this may because the greater part of ICU nurses worked with the task-based system in which their responsibilities were distributed according to the performance and level of skills in each shift which may reflect a negative attitude for delirium recognition and assessment.

Moreover, delirium is a global manifestation of brain dysfunction in which its hyperactive form has markedly different clinical manifestations than hypoactive form that makes it difficult to be recognized by ICU staffs. These results come in accordance with Flagg et al., [23] who found a low confidence in the determination of delirium with the CAM-ICU has been found previously. Suh and Yoo[24] and Elfeky and Ali [25] indicated that delirium was not considered an important problem to address, as well as there is still a difference in the perceived importance of delirium and motivation to invest in screening and prevention. Actually, from researcher point of view, these results reflect the importance of encouraging the critical care nurses for attending different training programs and continuing education to update their knowledge of delirium, in addition to increase the enhancement of their ability to recognize delirium especially almost of them are young adult that easy to acquire knowledge and change their perception and attitude.

Delirium is a very serious problem which increases morbidity, prolongs hospital stay, and threatens patient's safety [7,26,27] Evidence from previous studies suggests that delirium is associated with many negative outcomes [19]. Regarding the reported practice of studied subjects to delirium among children in ICUs the results stated that more than three quarter of them had unsatisfactory level of practice with a mean score $4.9 \pm 1.6$, inspite of most of nurses disagree that evaluating consciousness level is not the best method for delirium assessment they also disagree that delirium doesn't continue for more than hours, we should speak by loud voice and avoid eye contact for delirium child, as well as disagree about using of benzadiazeben, encouraging child to sleep and apply infection control measures will help in treating delirium (Table 4, Figure 3). This unsatisfactory practice may results from their poor knowledge and their negative attitude toward delirium as well as may because lack of studied nurses' autonomy as they expected to obtain direction on patient care from physicians. This results contradicted with [21] who founded that The majority of the respondents were frequently performed promotion of day time wakefulness (81\%), use of glasses when patients are visually impaired (74\%) and use of hearing aids when patients are hearing impaired (67\%). However, Yue et al., [20] explained unsatisfactory delirium practice from the side of nurses resulting from the lack of knowledge, absence of evidence-based nursing practice, complex symptoms, and changing shifts which leads to difficulties in detecting the early delirium signs.

As regard studied nurses reported barriers of delirium screening at pediatric intensive care units, the current results stated that common barrier was absence of tool to evaluate delirium in ICUs, difficult to determine delirium in children on ventilator, inefficient of symptoms registering in children taking sedation, doctors already 
determine delirium symptoms and evaluate and finally doctors do not consider nurses delirium evaluation respectively (Table 5). This may due to different hospital delivery system as the study performed at university and ministry of health hospitals, moreover, more than one third of studied nurses have from 5 to less than 10 years experience in ICUs. The result contradicted with Ozsaban and Acaroglu [28] who found that more than half of the participated nurses performed routine assessment of delirium, the majority of those nurses requested psychiatric consultation for the diagnosis of delirium and very few use delirium assessment tools. As well as the majority of the nurses identified delirium in patients on mechanical ventilation and more than half of the study nurses were conducting delirium assessment in patients with sedation. However, Scelsi et al. [29] determined that $12 \%$ nurses use formal assessment tools. Van Eijk [30] found in his study that $7 \%$ of nurses used it which is consistent with the literature that emphasized that nurses who use delirium assessment tools was found to be little. Finally , pediatric nurses working at intensive care units needs learning awareness with bulk of evidence-based knowledge and practice about pediatric delirium to change their negative attitude and improve their skills in screening it. Also they are in need for reliable delirium assessment instrument to monitor delirium symptoms.

\section{Conclusion}

Based on the findings of the present study, the following can be concluded that:

- The majority of studied nurses have poor knowledge about pediatric delirium particularly for its definition, causes and its management.

- More than half of the studied nurses has negative attitude regarding delirium and majority of them has unsatisfactory practice.

- The common barrier for delirium screening was absent of tool and difficulties of delirium screening for children on ventilator at ICUs.

\section{Recommendations}

In the light of the findings of the present study, the following recommendations are suggested:

- Nurses learning needs assessment should be assessed constantly and progressively.

- Educational training program to increase competences of Pediatric ICUs staff focused on delirium causes. Risk factors, prevention and practical guidelines of hospitalized children with delirium.

- Develop delirium assessment tools and protocols that enable the assessment of pediatric delirium routinely.

- Encouraging the provision of patient-centered care system rather than task-based patient care could contribute to improving quality of the care provided.

- Replication of the current study on large probability sample and various setting in Egypt to generalize the results.

\section{References}

[1] American Psychiatric Association. (2013). Neurocognitive disorders. In: Diagnostic and statistical manual of mental disorders. Washington: American Psychiatric Association; 591-643.

[2] Schieveld JNM, Ista E, Knoester H, \& Molag ML. (2015). Pediatric delirium: A practical approach. In Rey JM (ed), IACAPAP -Textbook of Child and Adolescent Mental Health. Geneva: International Association for Child and Adolescent Psychiatry and Allied Professions.

[3] Harroche J. St-Louis L \& Gagnon M. (2014). The detection of delirium in the ICU: An important aspect of care. Journal of Nursing Education and Practice, 4(9). www.sciedu.ca/jnep.

[4] Hatherill S \& Flisher AJ (2010). Delirium in children and adolescents: A systematic review of the literature. Journal of Psychosomatic Research, 68:337-344.

[5] Van Dijk M, Knoester H, van Beusekom BS et al (2012) Screening pediatric delirium with an adapted version of the Sophia Observation Withdrawal Symptoms Scale (SOS). Intensive Care Medicine, 38: 531-532.

[6] Jeffery A, Mutsch K, \& Knapp L. (2014). Knowledge and Recognition of SIRS and Sepsis among Pediatric Nurses. Pediatric Nursing, 40(6) 271-278.

[7] Arend E, and Christensen M. (2009). Delirium in the intensive care unit: a review. Nursing in Critical Care; 14: 145-154.

[8] Ely EW, Shintani A, Truman B, Speroff T, Gordon SM, Harrell FE, Inouye SK, Bernard GR, \& Dittus RS. (2004a).Delirium as a predictor of mortality in mechanically ventilated patients in the intensive care unit. Journal of American Medical Association; 291: 1755-1762.

[9] Brummel, N. E., Jackson, J. C., Pandharipande, P. P., Thompson, J. L.Shintani, A. K., Dittus, R. S., \& Girard, T. D. (2014). Delirium in the ICU and subsequent long-term disability among survivors of mechanical ventilation. Critical Care Medicine, 42, 369-377.

[10] Silver, G., Traube, C., Kearney, J., Kelly, D., Yoon,M. J., NashMoyal, W., \& Ward, M. J. (2012). Detecting pediatric delirium: Development of a rapid observational assessment tool. Intensive Care Medicine, 38, 1025-1031.

[11] Ely EW, Stephens RK, Jackson JC, et al (2004). Current opinions regarding the importance, diagnosis, and management of delirium in the intensive care unit: a survey of 912 healthcare professionals. Crit Care Med.; 32(1):106-112.

[12] Lee W Y,. Kim G C, Kong S E, Kim B K, Kim C N, Kim K H, Song S M, Ahn Y S, Lee J K, Chang O S, Chon J S , Cho O N, Cho O M \& Choi S K. (2007).A Study of Nurses' Knowledge Level and Assessment Experience of Delirium. Korean Journal of Adult Nursing, vol. 19, no. 1, pp. 35-44.

[13] Park S Y, and Gu O M. (2013). The Development and Effects of Evidence-based Nursing Practice Guideline for Cancer Patients with Delirium. Evidence and Nursing; vol. 1(1), 4-15.

[14] Glynn L, \&Corry M. (2015). Intensive care nurses' opinions and current practice in relation to delirium in the intensive care setting. Intensive Crit Care Nurs. 31(5): 269-75.

[15] EL Nossary A, Ismail M, Sultan M, \& Abdel kader F. (2016). Nurses' Knowledge And Practices About Delirium Among Intensive Care Units Patients At Emergency Hospital, Mansoura University. Mansoura Nursing Journal 3(2).

[16] Van de Steeg L, IJkema R, Wagner C \& Langelaan M, (2015). The effect of an e-learning course on nursing staff's knowledge of delirium: a before-and-after study BMC Medical Education15:12

[17] Mehrez M, Morsy W, Elshamy K, El-Hady M. (2016). Pressure Ulcer among Critical Care patients: Critical Care Nurses' Knowledge, Perception and Practice. Master thesis, Faculty of Nursing. Mansoura University.

[18] Zanaty M, Morsy W, El-shamy K, \& Ali SH. (2016). Critical Care Nurses Knowledge And Practices about sepsis bundle among critically ill patients at Emergency Hospital, Mansoura University Mansoura Nursing Journal 3(1).

[19] Ping G, Wang L, Yu Z, Ping C, Hao X, Bao-Li C, Yue J \& Xiangming F. (2009). Survey of attitudes and behaviors of healthcare professionals on delirium in ICU. Chinese Journal of Traumatology . 12(6): 328-333.

[20] Yue P, Wang L, Liu C, Wu Y. (2015). Qualitative study on experience of nurses caring for patients with delirium in ICUs in China: Barriers, Burdens and decision making dilemmas. International Journal of Nursing Sciences. 2-8. 
[21] Trogrlic Z', Ista E, Ponssen H, Schoonderbeek F G, Schreiner F, Verbrugge S, Dijkstra A, Bakker A \& van der Jagt A (2016). Attitudes, knowledge and practices concerning delirium: a survey among intensive care unit professionals. British Association of Critical Care Nurses 33(1): 244-56.

[22] Flaigle M C, Ascenzi J, \& Kudchadkar S R (2016). Identifying Barriers to Delirium Screening and Prevention in the Pediatric ICU: Evaluation of PICU Staff Knowledge. J Pediatr Nurs., 31(1): 81-84.

[23] Flagg B, Cox L, McDowell S, Mwose JM \& Buelow JM. (2010) Nursing identification of delirium. Clinical Nurse Specialist; 24: 260-266.

[24] Suh J H, \&Yoo S Y. Intensive (2007). Care Unit Nurse's Knowledge, Nursing Performance, and Stress about Delirium. Korean Journal of Adult Nursing, 19(1), 55-65.

[25] Elfeky A.H. \& Ali S.F. (2013). Nurses' Practices and Perception of Delirium in the Intensive Care Units of a Selected University Hospitals in Egypt. Journal of Education and Practice. 4(19).
[26] Ouimet S, Riker R, Bergeon N, Cossette M, Kavanagh B, \& Skrobik Y. (2007). Subsyndromal delirium in the ICU: evidence for a disease spectrum. Intensive Care Medicine; 33: 1007-1013.

[27] Brooks M: (2017). Delirium in Critically Ill Children Common May Go Undetected Reuters. Health Information, April (6).

[28] Ozsaban A \& Acaroglu R. (2015). Delirium assessment in intensive care units: practices and perceptions of Turkish nurses. British Association of Critical Care Nurses. 21 (5).

[29] Scelsi S, Giusti GD, Federica P, \& Sandra S. (2011). Italian nurses'perception of delirium in ICU: a survey. 4th EfCCNa Congress and FSAIO Spring Congress, Denmark.

[30] Van Eijk MMJ, Kesecio glu J, \& Slooter AJC. (2008). Intensive care delirium monitoring and standardised treatment: a complete survey of Dutch intensive care units. Intensive and Critical Care Nursing; 24: 218-221. 